\title{
Spontaneous Resolution of Portal Vein Thrombosis
}

\author{
Vishnu Banumukala Adarsh Babu \\ Department of Gastroenterology, Diana, Princess of Wales Hospital, Northern \\ Lincolnshire and Goole Hospitals NHS Trust, Grimsby, UK
}

\section{Key Words}

Portal vein thrombosis . Spontaneous resolution - Outcome

\begin{abstract}
A 56-year-old male was admitted with symptoms of belching, abdominal pain and weight loss of 2 weeks duration. Examination revealed hepatosplenomegaly which was confirmed by computed tomography (CT). CT images also revealed filling defects in the portal vein and intrahepatic branches consistent with thrombosis and hepatosplenic infarcts. Alkaline phosphatase was elevated at 688 units, all other investigations, including full blood count, coagulation screen and tumour markers, were normal. Magnetic resonance cholangiopancreatography did not reveal any mass in the porta hepatis. Upper gastrointestinal endoscopy and colonoscopy were normal. Liver biopsy was normal and did not reveal any evidence of lymphoma. The raised alkaline phosphatase settled to reference range over a period of 3 weeks. Thrombophilia screen was negative. Contrast CT of the abdomen performed after 4 weeks displayed revascularisation of the previously thrombosed portal vein and intrahepatic branches. The patient has remained asymptomatic since and we note spontaneous recanalisation of the previously occluded portal vein.
\end{abstract}

\section{Case Report}

A 56-year-old fit and healthy gentleman was admitted with symptoms of belching, mild abdominal pain and weight loss of 2 weeks duration. Examination revealed hepatosplenomegaly which was confirmed by abdominal computed tomography (CT). CT also demonstrated filling defects in the portal vein and its intrahepatic main branches consistent with thrombosis and hepatosplenic infarcts (fig. 1 , fig. 2 , fig. 3 , fig. 4). Additional evaluation by magnetic resonance imaging (MRI) did not reveal any lesion in the porta hepatis. Blood investigations revealed elevated alkaline phosphatase at 688 units. Full blood count, coagulation screen, thrombophilia screen and tumour markers were normal. The patient's symptoms improved during the hospital stay. No intervention was carried out with respect to anticoagulation or surgical procedure. The patient had upper gastrointestinal endoscopy to rule out varices and colonoscopy which did not reveal any lesion. Liver biopsy, performed to exclude lymphoma, was normal. The patient was discharged and followed up 4 weeks later. Contrast CT and MRI demonstrated revascularisation of the previously thrombosed portal vein and resolution of infarcts in the liver and spleen (絪. 5 , fig. 6 , fig. 7 , fig. 8). 


\begin{tabular}{r|l|l|l} 
Case Reports $/$ Ch & $\begin{array}{l}\text { Case Rep Gastroenterol 2008;2:373-379 } \\
\text { Dol: } 10.1159 / 000164619\end{array}$ & Published online: November 7, 2008 & $\begin{array}{l}\text { I 2008 S. Karger AG, Basel } \\
\text { ISSN 1662-0631 } \\
\text { www.karger.com/crg }\end{array}$ \\
& & & \\
\hline
\end{tabular}

\section{Discussion}

Portal vein thrombosis (PVT) is rare but can occur with any condition predisposing to thrombosis [1]. The population prevalence of PVT is around $1 \%$ and mostly secondary to hepatic cirrhosis (28\%). Next comes primary (24\%) and secondary hepatobiliary malignancy (20\%). 10\% have been implicated with major abdominal infections or inflammatory disease and $3 \%$ with myeloproliferative disorder. It is idiopathic in $14 \%$, as in the above case [2]. PVT is an important cause of portal venous hypertension after hepatic cirrhosis [3].

The signs and symptoms of PVT can be subtle or nonspecific as in our case or they can be overshadowed by those of the underlying illness [4]. Abdominal pain, gastrointestinal haemorrhage due to esophageal varices, hepatosplenomegaly, ascites and portal systemic encephalopathy are recognised clinical features [5]. Sometimes it is a radiological diagnosis.

The preferred investigations include duplex ultrasonography and/or colour Doppler ultrasonography, CT and magnetic resonance angiography (MRA). Plain abdominal ultrasound may not be helpful in diagnosing PVT, sometimes clot with variable echogenicity may be depicted in the portal vein. Colour Doppler can accurately diagnose PVT. Although in most patients ultrasound is the initial investigation, our patient had CT scan of the abdomen first and ultrasound scan of the abdomen later as the sensitivity of thrombus characterisation is reportedly low in CT although if seen it complements the diagnosis [6].

Thrombus has low attenuation on CT and is hyperintense on MRI. Hepatic infarcts usually appear as well-circumscribed, peripheral, wedge-shaped areas of decreased attenuation at CT as in this patient. The causes of PVT can be most readily identified with MRI [7]. MRA where available can be used to image the portal vein. If these procedures are unsatisfactory, digital subtraction angiography can be performed.

The prognosis of PVT is good in patients without underlying disease [8]. Treatment options include mechanical recanalisation of the portal vein, systemic anticoagulation, local fibrinolysis with or without placement of a transjugular intrahepatic portosystemic stent shunt, combination of mechanical recanalisation and local fibrinolysis and surgical thrombectomy. Sheen et al. suggest that if acute PVT is found, patients have to be treated with anticoagulant therapy. Anticoagulation decreases the risk of thrombotic events by two thirds [9]. Immediate anticoagulation is important in preventing serious consequences of portal and mesenteric vein occlusion. Recurrence of PVT is not known to occur. 


\begin{tabular}{r|l|l|l} 
Case Reports in & $\begin{array}{l}\text { Case Rep Gastroenterol 2008;2:373-379 } \\
\text { D0I: 10.1159/000164619 }\end{array}$ & Published online: November 7, 2008 & $\begin{array}{l}\text { O 2008 S. Karger AG, Basel } \\
\text { ISSN 1662-0631 } \\
\text { www.karger.com/crg }\end{array}$ \\
\hline
\end{tabular}

Fig. 1. CT performed at initial presentation shows hypodense areas in the liver and spleen suggesting infarct.

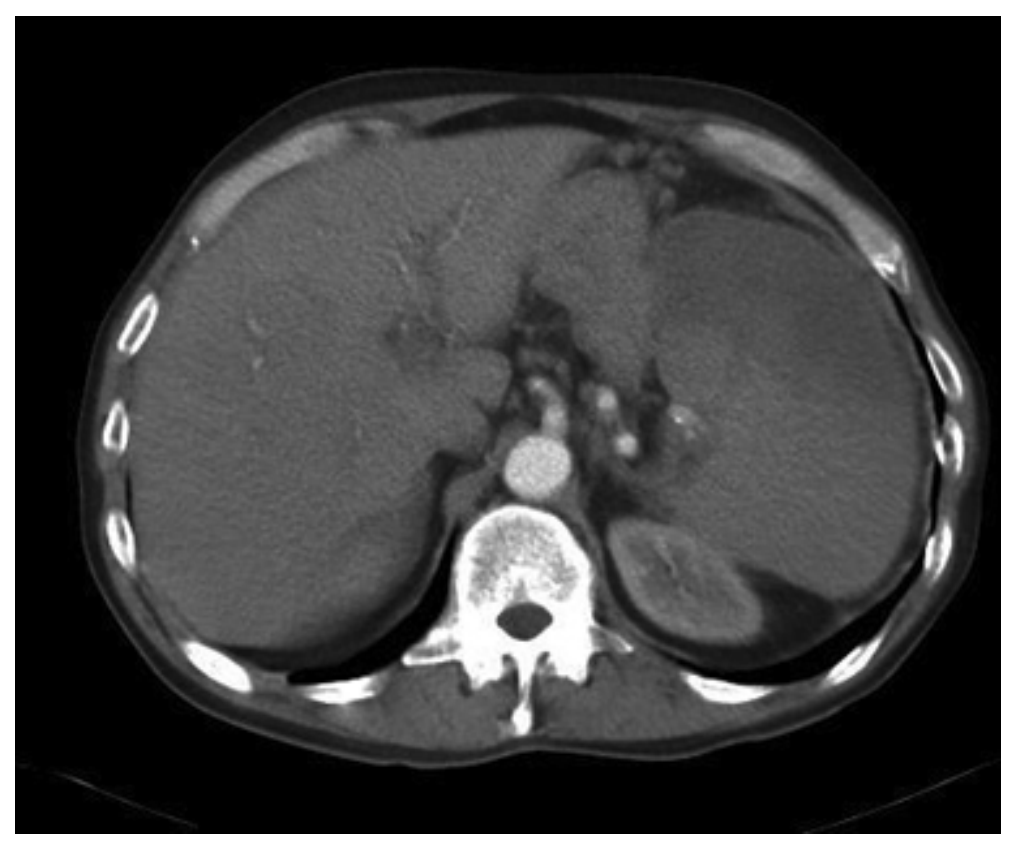

Fig. 2. Hypodense area in the liver and spleen suggesting infarct.

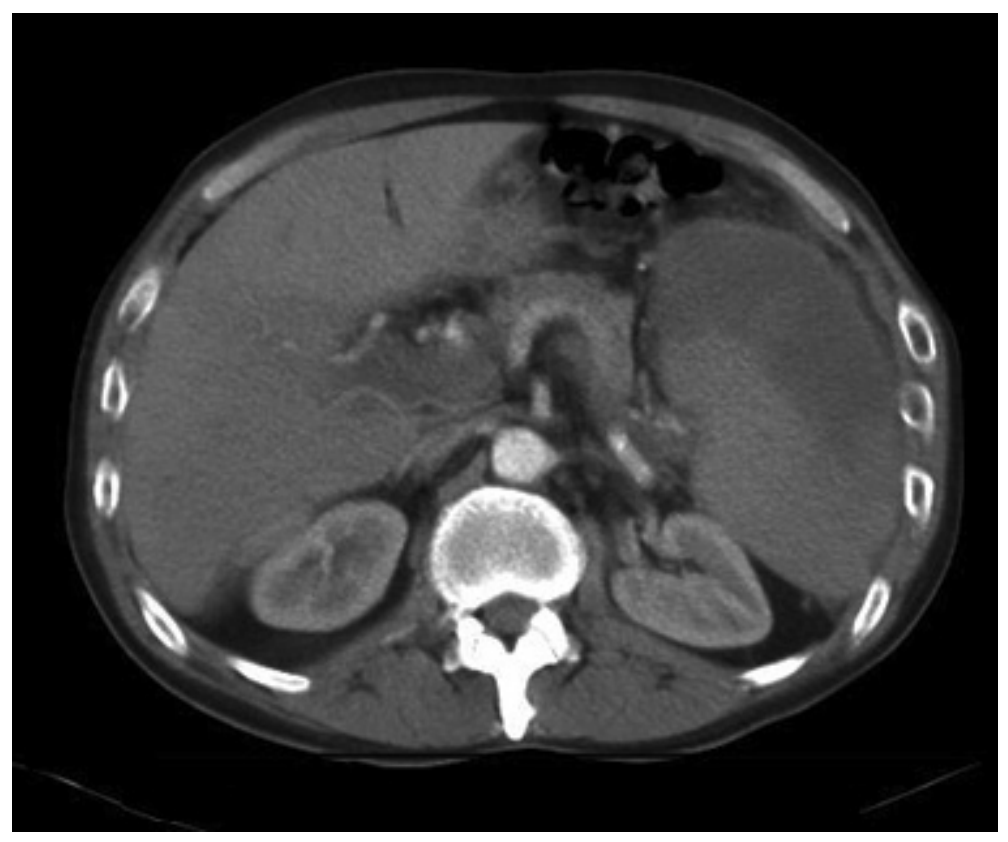




\begin{tabular}{r|l|l|l} 
Case Reports in & $\begin{array}{l}\text { Case Rep Gastroenterol 2008;2:373-379 } \\
\text { D0I: 10.1159/000164619 }\end{array}$ & Published online: November 7, 2008 & $\begin{array}{l}\text { O 2008 S. Karger AG, Basel } \\
\text { ISSN 1662-0631 } \\
\text { www.karger.com/crg }\end{array}$ \\
\hline
\end{tabular}

Fig. 3. Another section through the liver demonstrating infarcts around the porta hepatis.

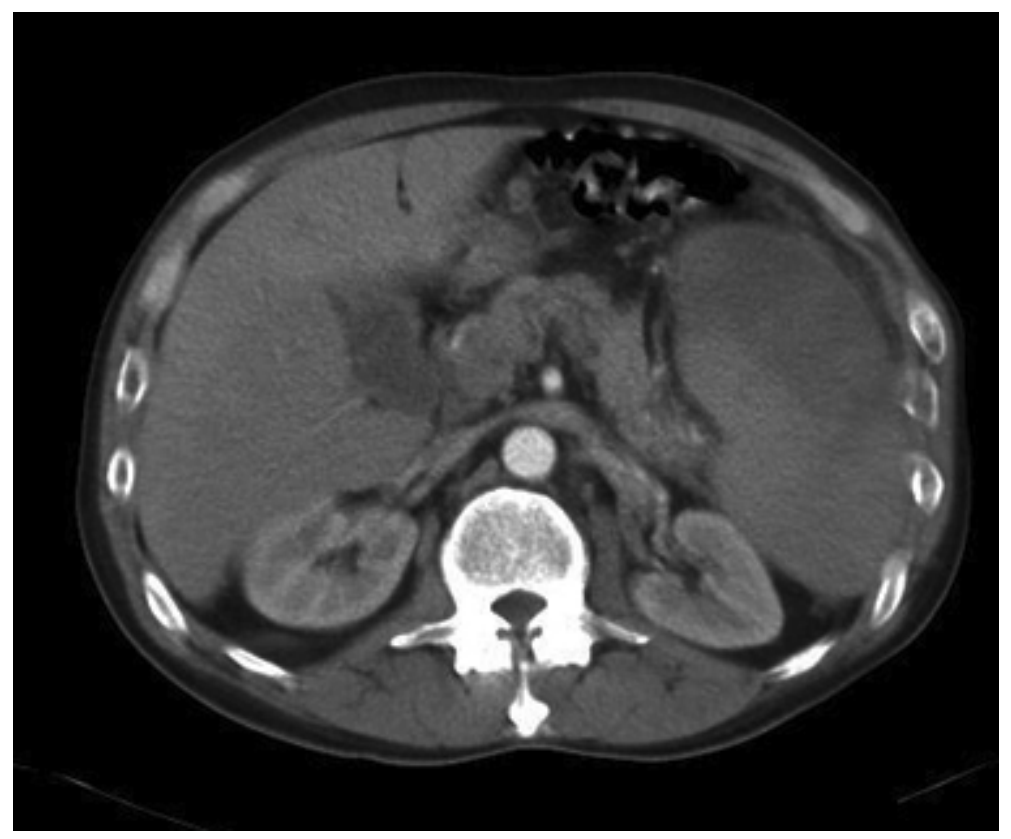

Fig. 4. Another section through the liver and spleen.

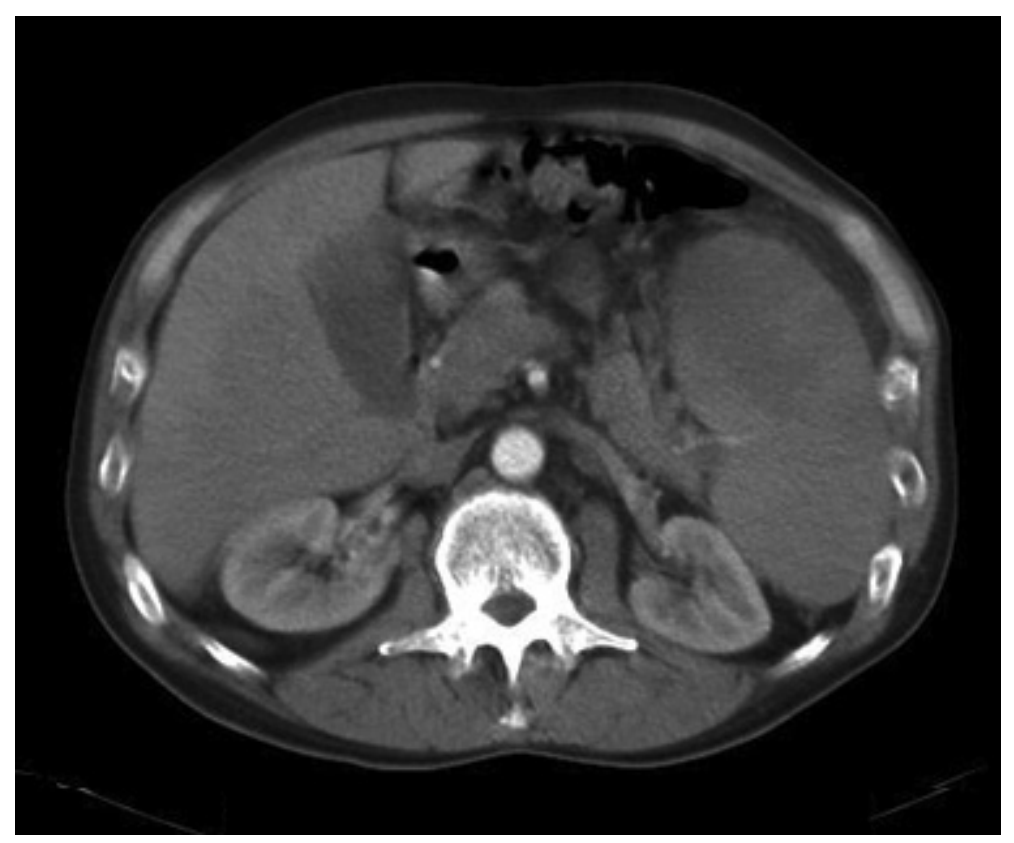




\begin{tabular}{r|l|l|l} 
Case Reports in & $\begin{array}{l}\text { Case Rep Gastroenterol 2008;2:373-379 } \\
\text { D0I: 10.1159/000164619 }\end{array}$ & Published online: November 7, 2008 & $\begin{array}{l}\text { O 2008 S. Karger AG, Basel } \\
\text { ISSN 1662-0631 } \\
\text { www.karger.com/crg }\end{array}$ \\
\hline
\end{tabular}

Fig. 5. CT of the liver and spleen performed 4 weeks after initial CT demonstrating resolving infarcts.

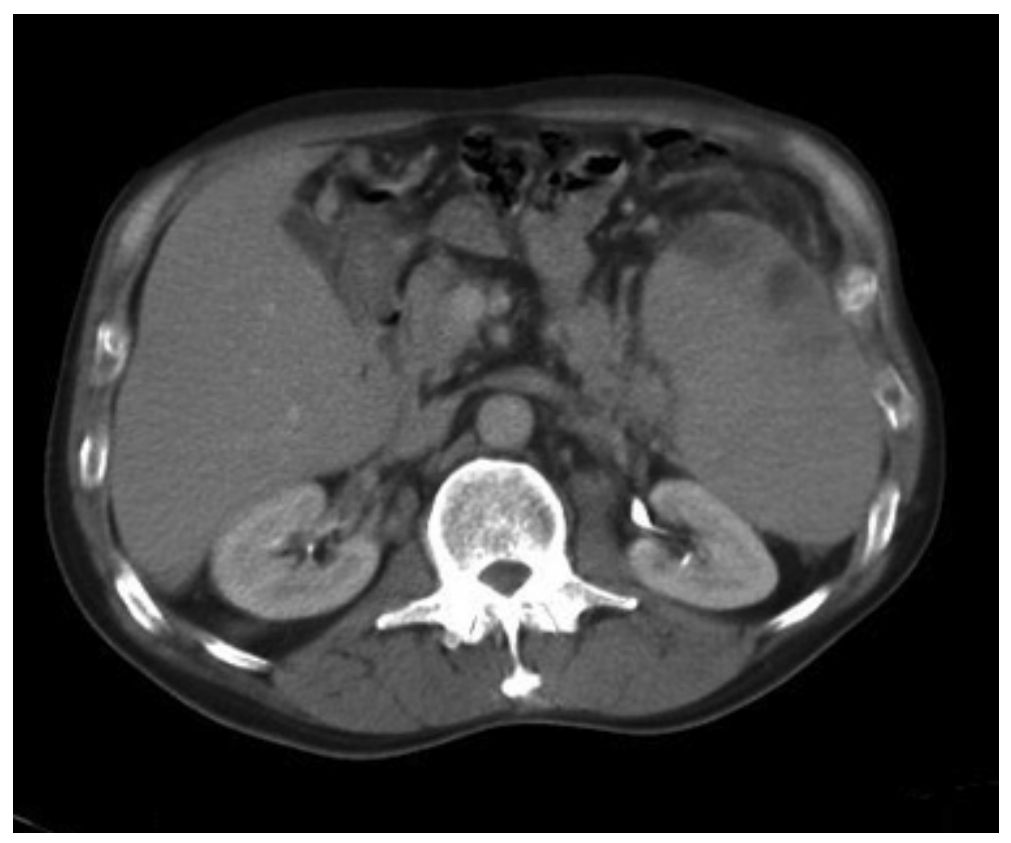

Fig.6. Another section through the liver and spleen 4 weeks later.

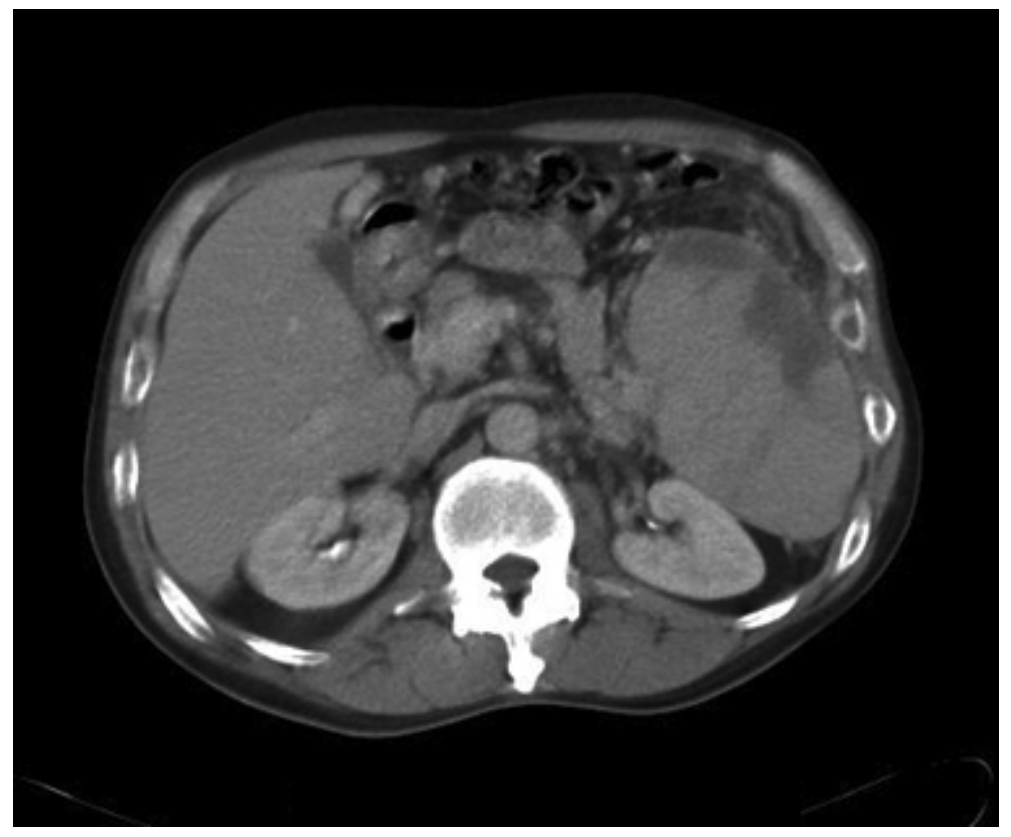




\begin{tabular}{r|l|l|l} 
Case Reports $/ \mathrm{h}$ & $\begin{array}{l}\text { Case Rep Gastroenterol 2008;2:373-379 } \\
\text { D01: 10.1159/000164619 }\end{array}$ & Published online: November 7, 2008 & $\begin{array}{l}\text { I 2008 S. Karger AG, Basel } \\
\text { ISSN 1662-0631 } \\
\text { www.karger.com/crg }\end{array}$ \\
\hline
\end{tabular}

Fig. 7. Section through the liver and spleen showing almost complete resolution of infarct in the liver.

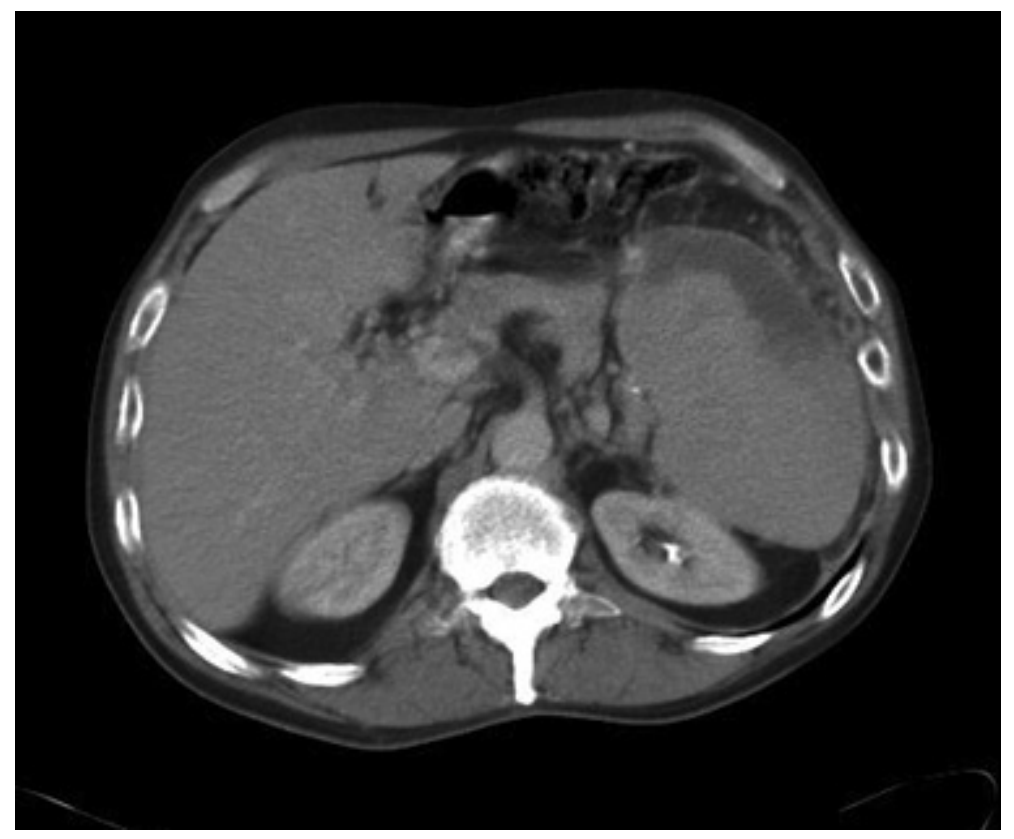

Fig. 8. MRI performed 4 weeks after initial CT also demonstrates resolution of infarcts in the liver and resolving infarcts in the spleen.

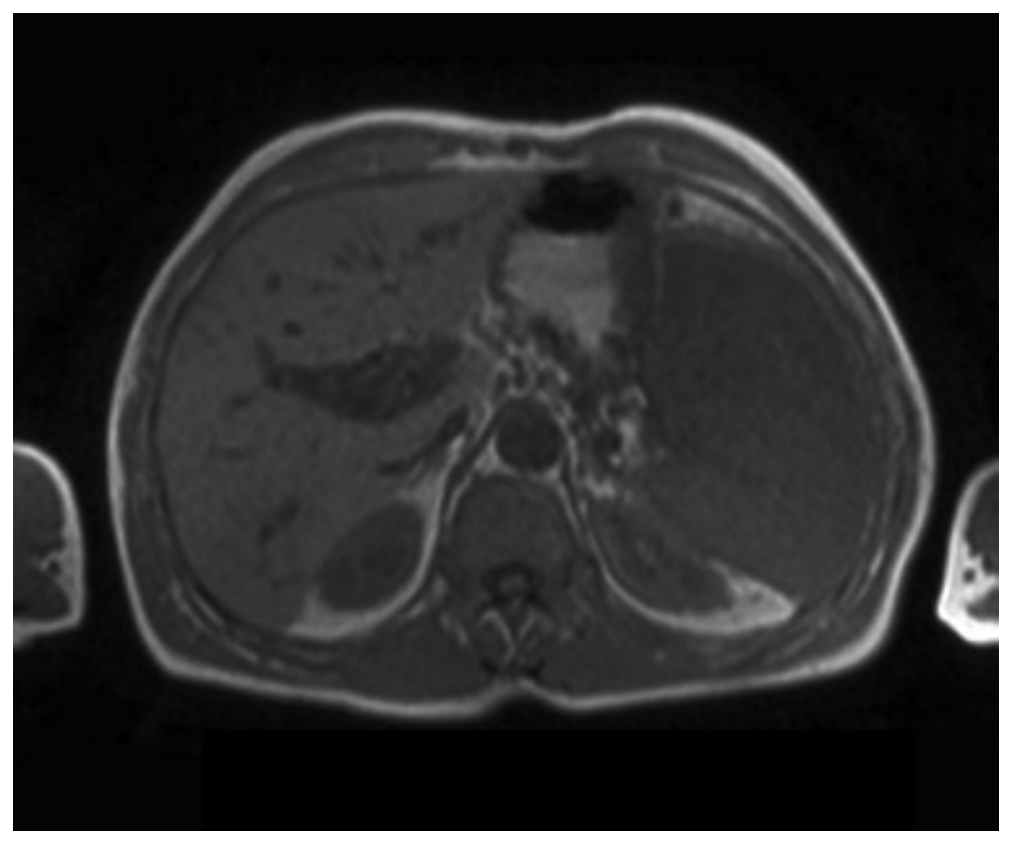




\section{References}

1 Haslett C, Chilvers ER, Boon NA: Davidson's Principles and Practice of Medicine, ed 19. Churchill Livingstone, 2002, p 541.

2 Fraser CJ, Newall F, Furmedge J, et al: Acute idiopathic portal vein thrombosis in a child: a case report and literature review. Thromb Res 2006;117:279-281.

-3 Wang JT, Zhao HY, Liu YL: Portal vein thrombosis. Hepatobiliary Pancreat Dis Int 2005;4:515-518.

4 Parvey HR, Raval B, Sandler CM: Portal vein thrombosis: imaging findings. AJR Am J Roentgenol 1994;162:77-81.

5 Khan AN: Liver, trauma. www.emedicine.com/radio/topic397.htm.

6 Rossi S, Rosa L, Ravetta V, et al: Contrast-enhanced versus conventional and color Doppler sonography for the detection of thrombosis of the portal and hepatic venous systems. AJR Am J Roentgenol 2006;186:763-773.

7 Kocher G, Himmelmann A: Portal vein thrombosis (PVT): A study of 20 non-irrhotic cases. Swiss Med Wkly 2005;135:372-376.

-8 Kawamoto S, Soyer PA, Fishman EK, Bluemke DA: Nonneoplastic liver disease: evaluation with CT and MR imaging. Radiographics 1998;18:827-848.

-9 Sheen CL, Lamparelli H, Milne A, Green I, Ramage JK: Clinical features, diagnosis and outcome of acute portal vein thrombosis. QJM 2000;93:531-534. 